\title{
Experimental Study on Axial Compression Behavior of Masonry Columns' Strengthening with Bamboo Scrimber Bar Mesh Mortar Layer
}

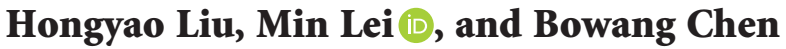 \\ Departments of Civil Engineering, University of Central South University of Forestry and Technology, Changsha 410000, China \\ Correspondence should be addressed to Min Lei; 26788829@qq.com
}

Received 23 September 2019; Accepted 16 January 2020; Published 15 February 2020

Academic Editor: Jorge Branco

Copyright (c) 2020 Hongyao Liu et al. This is an open access article distributed under the Creative Commons Attribution License, which permits unrestricted use, distribution, and reproduction in any medium, provided the original work is properly cited.

\begin{abstract}
We propose a new method to strengthen structural masonry. To study on the axial compression behavior of masonry columns' strengthening with a bamboo scrimber bar mesh mortar layer, axial compression tests of twelve masonry columns have been completed: nine strengthened columns and three unstrengthened columns. The failure process, bearing capacity, and failure mode are carried out. The strengthening method of bamboo scrimber bar mesh mortar layer permits the upgrade of the columns' bearing capacity. The effects of bamboo bar ratio and mortar strengthening ratio on bearing capacity of the reinforced columns are compared. We propose the method for calculating the axial bearing capacity of such a reinforced column. The calculation results agree well with the experimental results, and the research results are available for engineering application.
\end{abstract}

\section{Introduction}

Most of China's rural houses use self-built masonry structures. Self-built masonry structures often have many defects and high vulnerability. Because of the constraints of China's urbanization development stage and the current economic development, the existing self-built masonry structures in rural areas will be in existence for a long time. Therefore, it is a need to strengthen existing masonry structures.

Standard strengthening methods for masonry structures [1] include the reinforced concrete layer, the steel bar mesh mortar layer, the sectional steel frame, the externally prestressed strut, and the externally bonded fibre-reinforced polymer. In recent years, with the continuous development of new materials, researchers have invested more research into masonry structures' strengthening with new materials, and the research results are more and more. Zhang et al. [2] proposed a method of strengthening brick walls with embedded bars. Farooq et al. [3] and Darbhanzi et al. [4] studied the effects of steel strips' strengthening on the seismic performance of brick walls. Navaratnarajah and Kimiro [5] used PP-band meshes to enhance structural masonry. Deng et al.
[6] proposed a method for strengthening brick columns by using HDC (highly ductile fibre-reinforced concrete). Salman et al. [7] used sprayable eco-friendly ductile cementitious composite (EDCC) to strengthen unreinforced masonry walls. Yamamoto and Meguro [8] developed a new fibrereinforced concrete for retrofitting of structural masonry. The research results showed that the traditional strengthening method and the new retrofitting method could improve the bearing capacity of the masonry structures. However, some methods are challenging to construct, some methods have higher steel consumption, and some methods have higher engineering costs, which are not suitable for wide use in rural areas of China.

Bamboo is a biomass material with a short growth cycle and excellent industrial performance. We know China is the kingdom of bamboo. According to statistics, there are 110 million tons of idle bamboo forest resources in China. The bamboo has a high tensile strength. However, bamboo prices are much lower than steel. The replacement of high-contamination, high-energy, nonrenewable steel bars in the structure with bamboo not only conforms to the current condition of China but also contribute to the sustainable 
development of the construction industry and protecting the environment.

At present, two examples of engineered bamboo are laminated: bamboo and bamboo scrimber [9]. In the process of industrial manufacturing, bamboo scrimber has been screened to eliminate the defects of the original bamboo and reduce moisture content. Therefore, bamboo scrimber has uniform mechanical properties: small variability, high strength, and excellent durability. It is possible for bamboo scrimber to replace steel bars in some structures and components. Domestic and foreign scholars have conducted some research on the properties of bamboo scrimber [10-12]. Nugroho and Ando [13] proved that the performance of bamboo scrimber board could meet the commercial product standard by studying the basic physical and mechanical properties. Huang et al. [14] conducted the tensile and compression tests in parallel to grain and perpendicular to grain, and the shear test in three directions to study the failure mechanism and stress-strain relationship of bamboo scrimber and obtained tensile elastic modulus, compressive elastic modulus, shear modulus, and stressstrain relationships. Sharma et al. [15] compared the mechanical properties of tensile, compressive, shear and bending of bamboo scrimber and laminated bamboo. The results show that the mechanical properties of bamboo scrimber are better than that of laminated bamboo. Xu e al. [16] studied on the stress-strain relationship and failure mechanism of bamboo scrimber at elevated temperatures. The research found the compressive stress-strain curves of bamboo scrimber exposed to elevated temperatures were divided into a linear branch and a nonlinear branch beyond the proportional limit for both grain directions.

This paper proposes a method of the bamboo scrimber bar mesh mortar layer to strengthen the masonry structures. Through the axial compression experiment, bearing capacity, ductility, failure form, and bamboo bar strain of the reinforced brick columns and the unreinforced brick columns are studied. Based on the experiment, the influence of parameters such as bamboo bar ratio and mortar strengthening ratio on bearing capacity of reinforced brick columns are analysed. A method for calculating the axial bearing capacity of such a reinforced brick column is proposed.

\section{Material and Methods}

2.1. Specimen Design. Four groups of specimens are designed for this experiment. There are three specimens in each group, thus forming a total of twelve specimens. All the brick columns are $370 \mathrm{~mm}$ wide, $240 \mathrm{~mm}$ thick, and $720 \mathrm{~mm}$ tall. The brick columns are composed of MU10 brick and M2.5 cement mortar. The brick columns are built on the reinforced concrete bases whose dimensions are $550 \mathrm{~mm}$ wide, $400 \mathrm{~mm}$ thick, and $200 \mathrm{~mm}$ tall and whose strength class is C30. After the specimens have been built and cured for seven days, the dirt and scraps on the surfaces of the specimens are removed. After drilling with an electric drill, L-shaped shear pins made of $\varphi 6$ rebar are implanted on the surfaces of the specimens. The shear pins are implanted to a depth of $60 \mathrm{~mm}$ and bonded by Goodbond modified epoxy adhesive. Bamboo scrimber bars are cut from bamboo scrimber plates produced by YiyangTaohuajiang Bamboo Development Co., Ltd. The section size of bamboo bars is $10 \times 10 \mathrm{~mm}$. A mixture of epoxy resin and polyamide resin is applied to the surfaces of bamboo bars. Then, sand is evenly spread on bamboo bars to enhance the bonding performance of bamboo bars and cement mortar. The longitudinal bamboo bars and horizontal bamboo bars are tied by steel wire. The bamboo bar mesh is fixed on the surfaces of the brick columns by the shear pins. Strengthened mortar with strength class M15 and $40 \mathrm{~mm}$ thick is applied to the brick columns for three times. The parameters of specimens are listed in Table 1. Figure 1 is the schematic diagram of specimens. Figure 2 shows the making and strengthening process of the bamboo bar mesh.

2.2. Material Properties. According to the method of Testing methods for physical and mechanical properties of bamboo used in building [17], the material properties of bamboo scrimber are tested. Table 2 shows the experimental test methods of bamboo scrimber. The material properties are given in Table 3.

The compressive strength of bricks and mortar is tested by the test method in Standard for test method of basic mechanics properties of masonry[18]. The measured compressive strength of the bricks is $12.0 \mathrm{MPa}$. The measured compressive strength of the masonry mortar and the strengthening mortar is given in Table 4 .

2.3. Loading Scheme. The experiment is carried out in the structural experiment hall of the College of Civil Engineering, University of Central South University of Forestry and Technology. Figure 3 is a diagram of the experimental loading device. The vertical axial load is centered and applied using a jack with $2000 \mathrm{kN}$ capacity. This jack is located on two steel plates $(225 \mathrm{~mm}$ wide $\times 225 \mathrm{~mm} \mathrm{long} \times 40 \mathrm{~mm}$ thick) that are placed on the specimen. A force sensor is placed on the jack. One steel plate $(225 \mathrm{~mm}$ wide $\times 225 \mathrm{~mm}$ long $\times 40 \mathrm{~mm}$ thick) and two steel plates $(400 \mathrm{~mm}$ wide $\times 400 \mathrm{~mm}$ long $\times 20 \mathrm{~mm}$ thick) are placed between the force sensor and the steel beam of the reaction frame.

This test is a monotonic static loading test using a step loading. Before loading, preload to $20 \mathrm{kN}$ for two minutes and then unload at a constant rate. Preloading is utilized to eliminate the gap between the loading device and the specimen and to check the sensitivity of the instrument and the firmness of the installation. After the preloading is completed, the load is gradually increased at a loading rate of $20 \mathrm{kN}$. After the specimen cracked, the load is increased at a loading rate of $10 \mathrm{kN}$ until the specimen fails. The failure load takes $85 \%$ of the peak load.

2.4. Measurement Scheme. From the experiment, it appears that the compressive load and vertical displacement of the columns and the strain of the bamboo scrimber bars are 
TABLe 1: Parameters of specimens.

\begin{tabular}{lccc}
\hline Specimen group & Vertical bamboo bar & Horizontal bamboo bar & Strengthening method \\
\hline ZA & - & - & - \\
ZB & $10 \times 10 @ 240$ & $10 \times 10 @ 220$ & Double sides \\
ZC & $10 \times 10 @ 120$ & $10 \times 10 @ 220$ & Double sides \\
ZD & $10 \times 10 @ 120$ & $10 \times 10 @ 220$ & Four sides \\
\hline
\end{tabular}

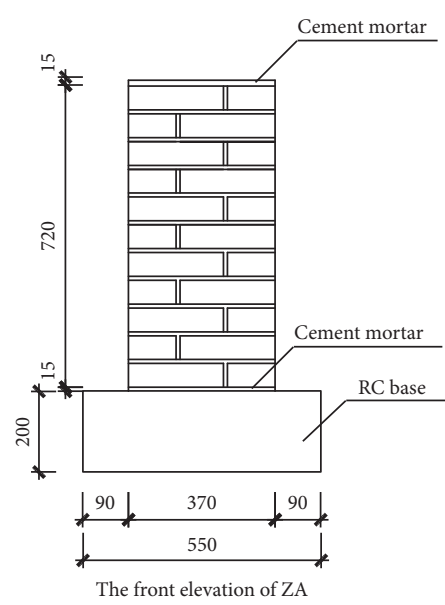

(a)

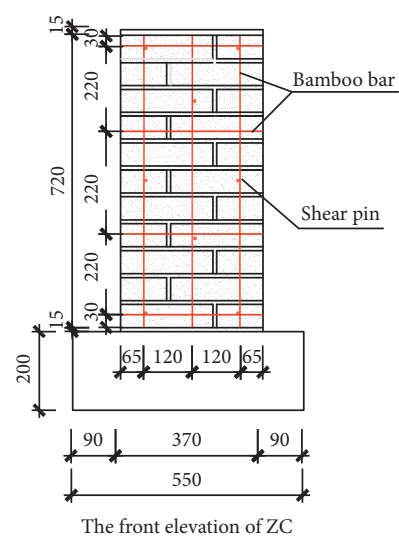

(e)

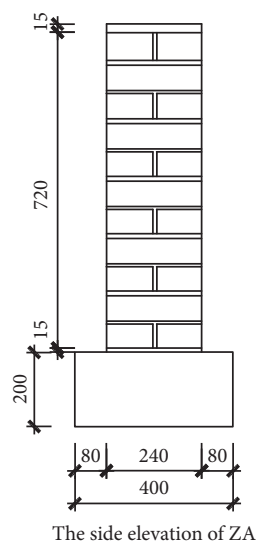

(b)

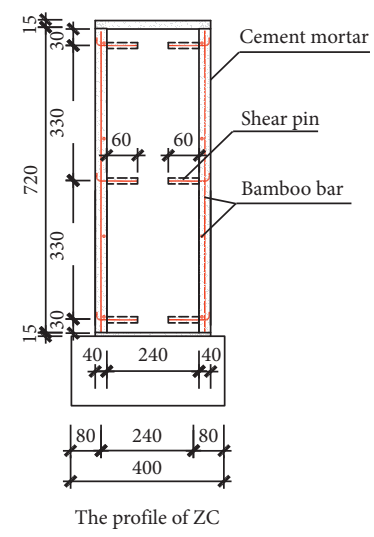

(f)

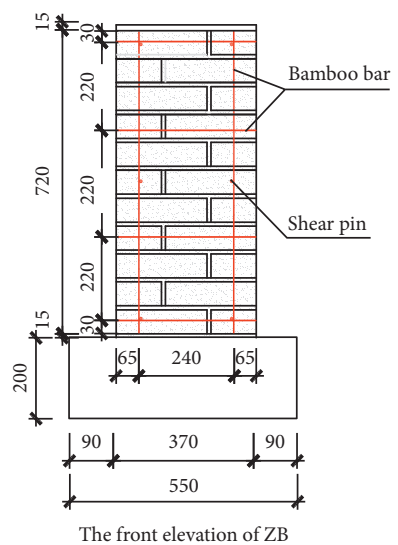

(c)

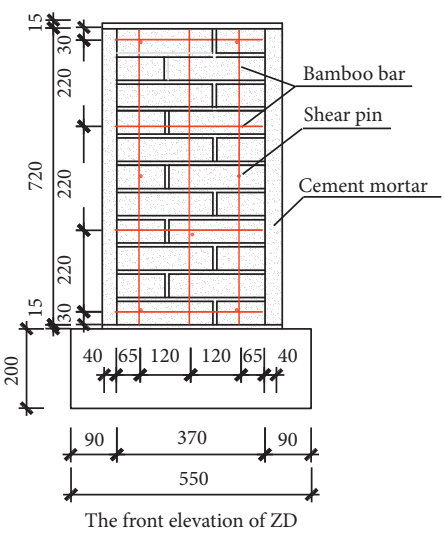

(g)

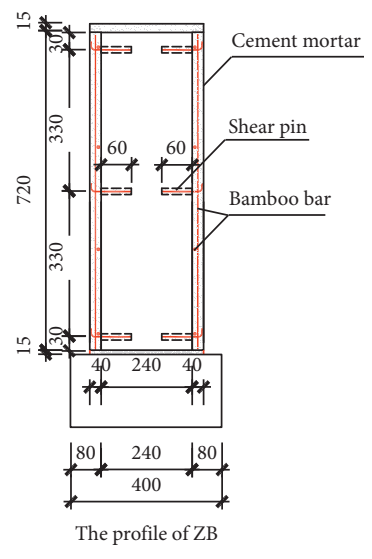

(d)

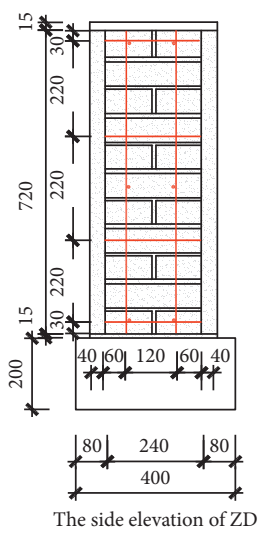

(h)

Figure 1: Schematic diagram of specimens.(a) The front elevation of ZA. (b) The side elevation of ZA. (c) The front elevation of ZB. (d) The profile of ZB. (e) The front elevation of ZC. (f) The profile of ZC. (g) The front elevation of ZD. (h) The side elevation of ZD.

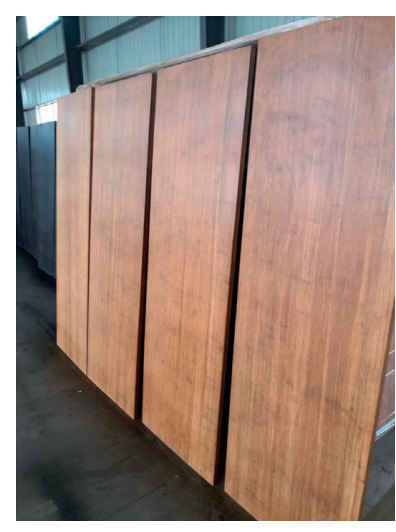

(a)

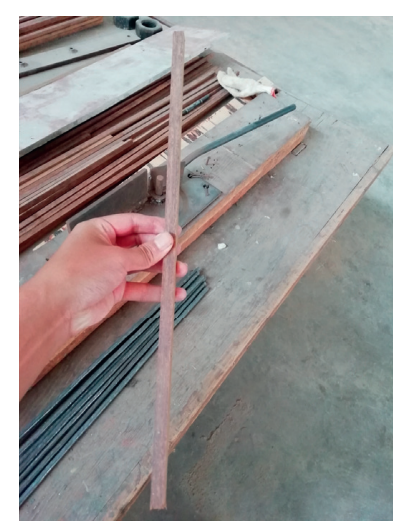

(b)

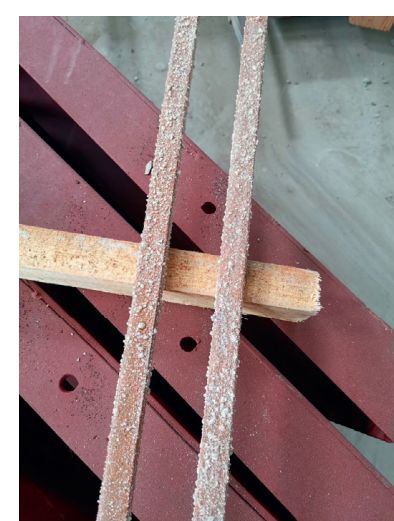

(c)

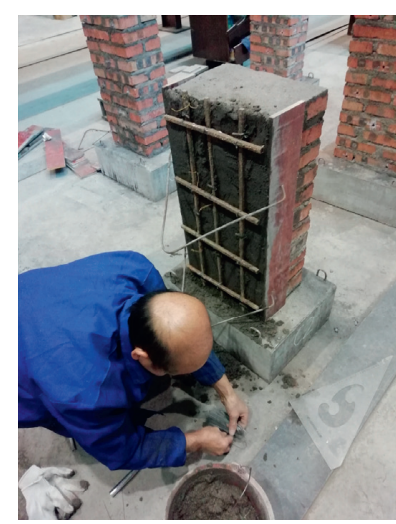

(d)

FigURE 2: The process of making bamboo scrimber bar: (a) bamboo board, (b) cutting into strips, (c) gluing sand, and (d) binding bamboo bars. 


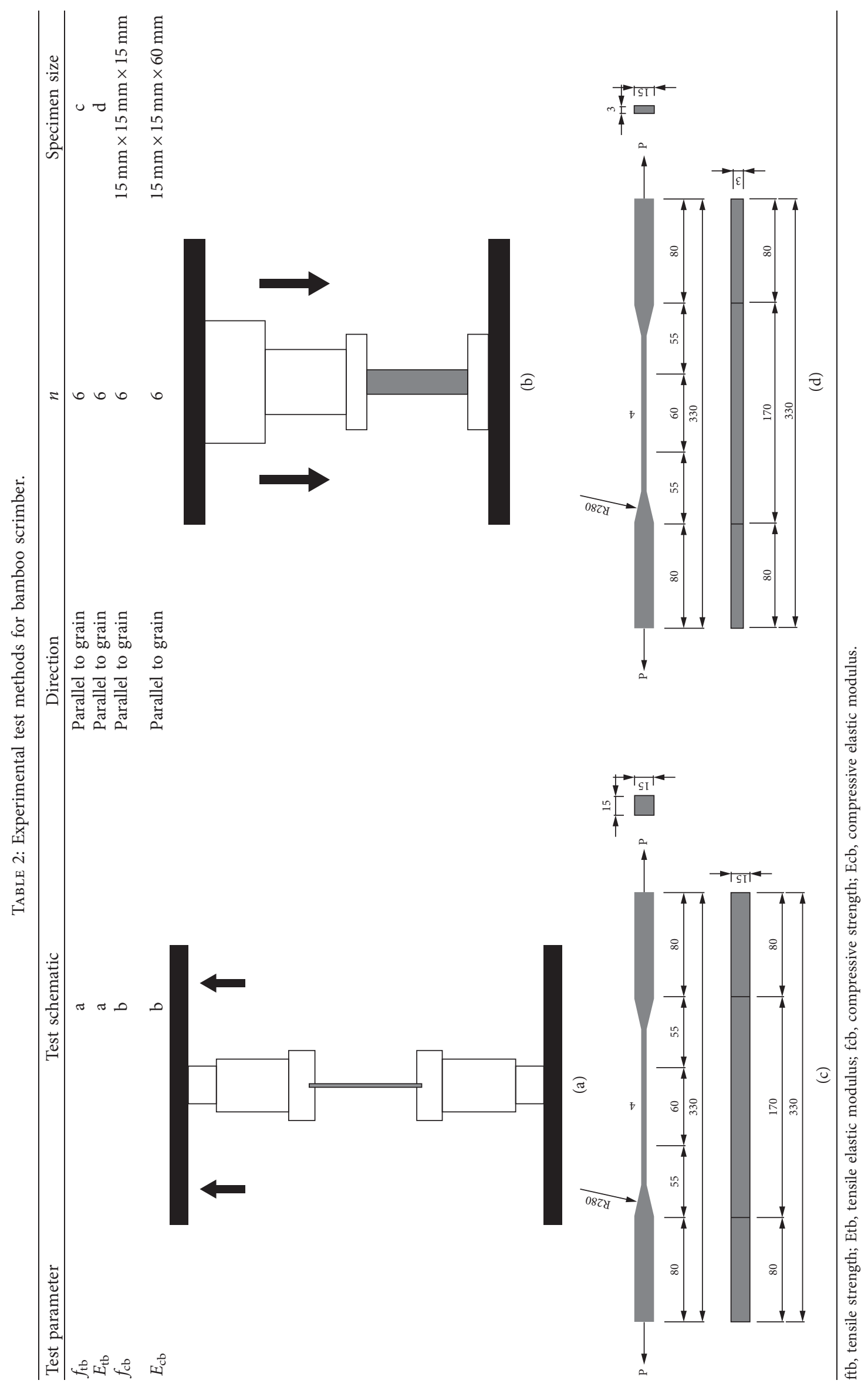


TABLE 3: Material properties for bamboo scrimber.

\begin{tabular}{lccc}
\hline$f_{\mathrm{tb}}(\mathrm{MPa})$ & $E_{\mathrm{tb}}(\mathrm{GPa})$ & $f_{\mathrm{cb}}(\mathrm{MPa})$ & $E_{\mathrm{cb}}(\mathrm{GPa})$ \\
\hline 158.61 & 21.28 & 91.50 & 4.55 \\
\hline
\end{tabular}

TABLE 4: Compressive strength of mortar.

\begin{tabular}{lcc}
\hline Specimens & $f_{\mathrm{c} 1}(\mathrm{MPa})$ & $f_{\mathrm{c} 2}(\mathrm{MPa})$ \\
\hline ZA1, ZA2, ZA3 & 2.86 & - \\
ZB1 & 2.86 & 9.60 \\
ZB2 & 2.86 & 9.60 \\
ZB3 & 2.86 & 10.58 \\
ZC1 & 2.56 & 13.70 \\
ZC2 & 2.56 & 13.70 \\
ZC3 & 2.56 & 8.66 \\
ZD1 & 2.56 & 14.37 \\
ZD2 & 2.56 & 10.09 \\
ZD3 & 2.56 & 9.49 \\
\hline
\end{tabular}

$f_{\mathrm{c} 1}$, masonry mortar compressive strength; $f_{\mathrm{c} 2}$, strengthened mortar compressive strength.

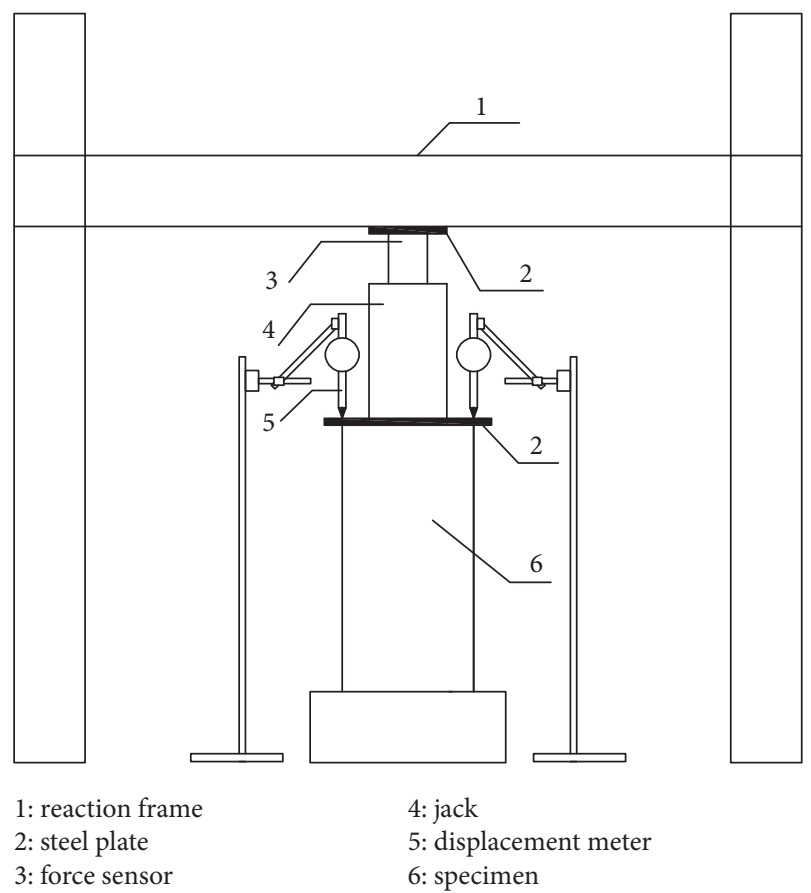

FIGURE 3: Loading device of specimens.

mainly tested. Figure 4 shows the arrangement position of the strain gauges on the bamboo bars.

\section{Results}

The average test values of the specimen groups are shown in Table 5. Figure 5 is a comparison diagram of the compressive load-displacement curves of typical specimens of the specimen groups.

After strengthening of the bamboo scrimber bar mesh mortar layer, the cracking load of the brick columns increased by $39.4 \%-67.2 \%$, and the peak load increased by $39.3 \%-113.5 \%$. Stiffness of the strengthening brick columns is significantly improved. However, the peak displacement increase is not apparent, and the increasing range is - $23.3 \%$ to $24.8 \%$. It indicates that the strengthening method cannot significantly increase the axial compression deformation performance of the brick columns due to the self-brittleness of the cement mortar layer.

Compared with group ZB, the longitudinal bamboo bars in group ZC brick columns are increased when the number of bar faces is the same, the cracking load of the brick columns increased by $8.25 \%$, the peak load increased by $19 \%$, and the peak displacement increased by $62.6 \%$. The increase of bamboo scrimber longitudinal bar not only improves the axial bearing capacity of the brick columns but also dramatically increases the ductility of the brick columns.

Comparing with group ZD and group ZC, the stiffness of the brick columns is significantly improved as the strengthening faces number increases. Four-sided strengthening has a restraining effect on the brick columns, which significantly increases the axial bearing capacity of the brick columns.

\subsection{Failure Process}

3.1.1. Specimen Group ZA. When the vertical load reaches about $50 \%$ of the ultimate load, several vertical cracks appear on the surfaces of the brick column. The width of the cracks increases continuously during the test. When the vertical load reaches about $80 \%$ of the ultimate load, the cracks extend rapidly upwards and downwards. As the load continues to increase, the vertical cracks penetrate, the masonry mortar begins to fall off, the vertical deformation and cracks of the brick column increase sharply, and the brick column is destroyed. Figure 6 indicates the typical failure mode of group ZA brick columns.

3.1.2. Specimen Group ZB. During the test, some horizontal cracks appear first on the strengthening surfaces corresponding to the horizontal bamboo bars when the vertical load increases to about $50 \%$ of the ultimate load. When the load is applied up to $70 \%$ of the ultimate load, several vertical cracks appear in the middle of the strengthening surfaces, two vertical cracks appear on the interface between the strengthening layers and the brick column, and new horizontal cracks appear on the strengthening surfaces corresponding to horizontal bamboo bars. With the load increases, the original cracks develop, and some other vertical cracks appear and extend. When the ultimate load is reached, the vertical cracks of the unreinforced surfaces penetrate, the horizontal cracks of the strengthening surfaces penetrate, the vertical deformation of the brick column increases continuously, and the brick column is destroyed. The typical failure mode of group ZB is shown in Figure 7.

3.1.3. Specimen Group ZC. Several vertical cracks appear on the strengthening surfaces corresponding to the middle longitudinal bamboo bars when the vertical load reaches about $50 \%$ of the ultimate load. When the load reaches about 


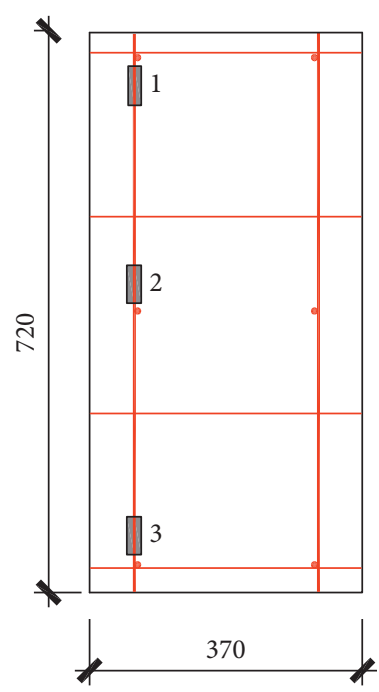

(a)

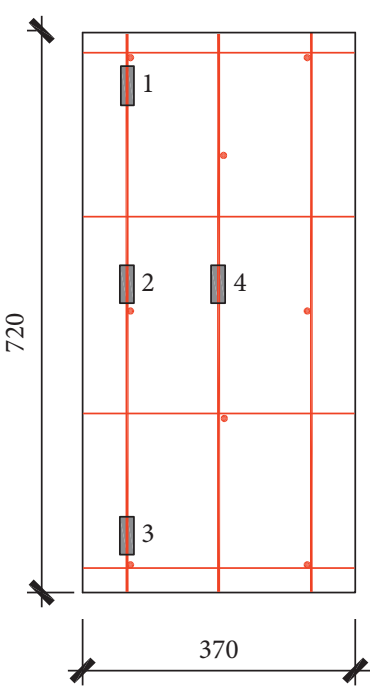

(b)

Figure 4: Layout of strain gauges: (a) ZB and (b) ZC and ZD.

TABLE 5: Test results average.

\begin{tabular}{lcccccc}
\hline $\begin{array}{l}\text { Specimen } \\
\text { group }\end{array}$ & $\begin{array}{c}\text { Cracking load } \\
(\mathrm{kN})\end{array}$ & $\begin{array}{c}\text { Increasing rate of } \\
\text { cracking load }(\%)\end{array}$ & $\begin{array}{c}\text { Peak load } \\
(\mathrm{kN})\end{array}$ & $\begin{array}{c}\text { Increasing rate of } \\
\text { peak load }(\%)\end{array}$ & $\begin{array}{c}\text { Peak displacement } \\
(\mathrm{mm})\end{array}$ & $\begin{array}{c}\text { Increasing rate of peak } \\
\text { displacement }(\%)\end{array}$ \\
\hline ZA & 287 & - & 561 & - & 2.764 & - \\
ZB & 400 & 39.4 & 736.7 & 31.3 & 2.121 & -23.3 \\
ZC & 433 & 50.9 & 876.7 & 56.3 & 3.449 & 24.8 \\
ZD & 480 & 67.2 & 1200 & 113.9 & 2.775 & 0.4 \\
\hline
\end{tabular}

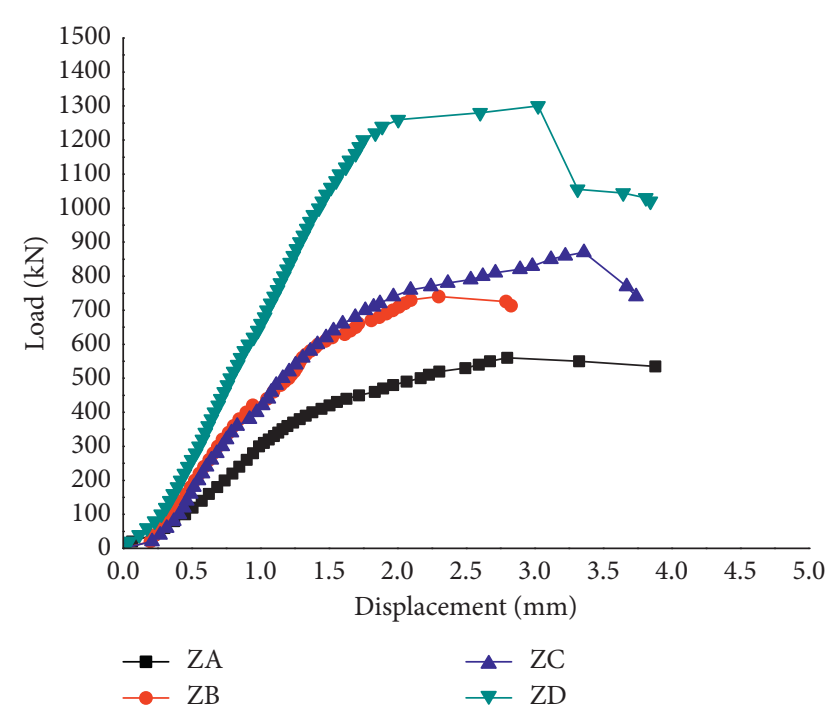

FIGURE 5: Load-displacement curves of typical specimens.

$70 \%$ of the ultimate load, some vertical cracks appear on the interface between the strengthening layers and the brick column. At the same time, new vertical cracks and horizontal cracks appear in the corresponding position of the bamboo bar mesh on the strengthening surfaces. When the load is applied up to $90 \%$ of the ultimate load, the original vertical cracks of the unreinforced surfaces extend and widen, and new vertical cracks appear in the middle of the brick column; the original horizontal cracks and vertical cracks of the strengthening surfaces extend faster, and some new vertical cracks appear simultaneously. When reaching the ultimate load, the vertical cracks of the unreinforced surfaces penetrate; the vertical cracks of the strengthening surfaces do not penetrate, but the horizontal cracks penetrate, and the mortar of the strengthening surfaces begins to fall off. Figure 8 shows the typical damage mode of group ZC brick columns.

3.1.4. Specimen Group ZD. When the load reaches about $40 \%$ of the ultimate load, the horizontal cracks appear on the four strengthening surfaces corresponding to the horizontal bamboo bars. As the load increases, the vertical crack appears in the corresponding position of the vertical bamboo bars. As the load continues to increase, the vertical and lateral cracks extend and widen, forming "\#”-shaped cracks on the strengthening surface. When the ultimate load is reached, the vertical cracks penetrate in the long-side strengthening surface; in the short-side strengthening surface, the horizontal cracks penetrate in the middle position, and the strengthening mortar layer is arched and separated from the brick column; the brick column is destroyed. After the experiment, the strengthening mortar layers are cut and observed. The bamboo bar mesh and the brick column are still tightly combined. In the corresponding position of the brick column and the strengthening surfaces, a plurality of vertical cracks penetrated. Figure 9 indicates a typical failure form of group ZD. 


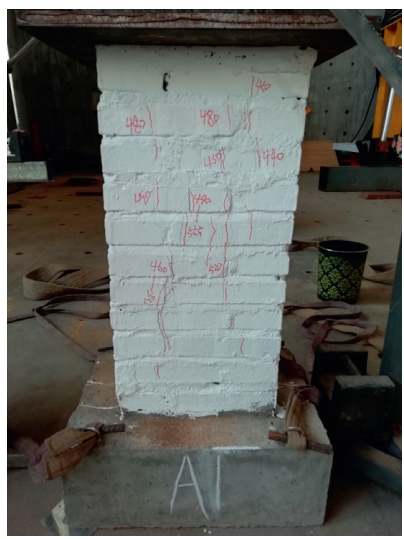

(a)

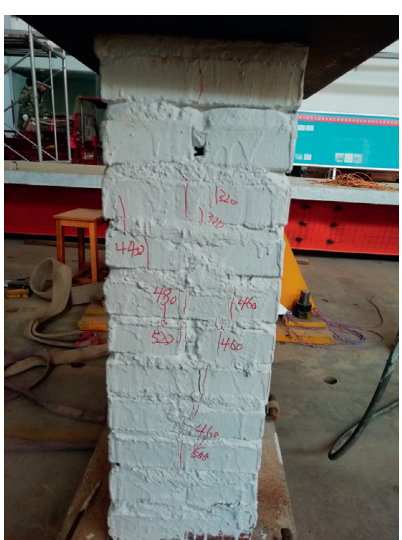

(b)

FIgURE 6: Typical failure of group ZA.

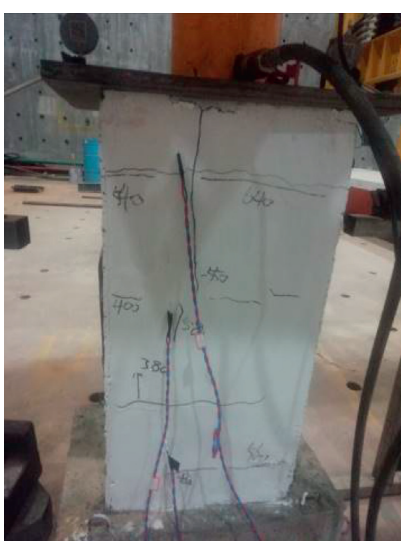

(a)

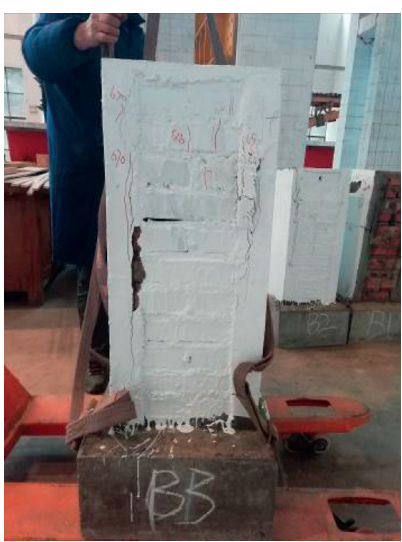

(b)

FIgURE 7: Typical failure of group ZB.

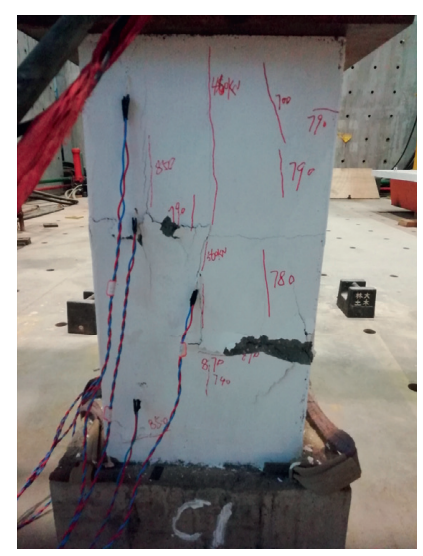

(a)

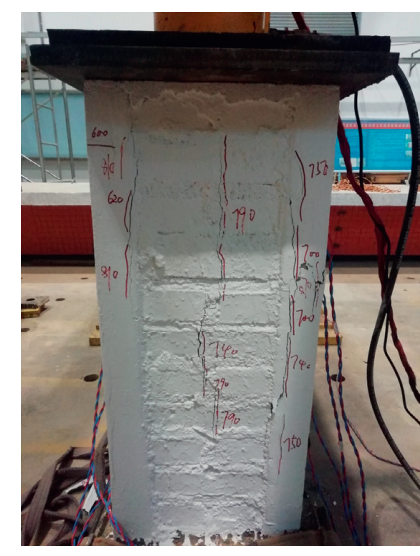

(b)

FIgURe 8: Typical failure of group ZC.

3.2. Strain of Bamboo bar. The vertical load-bamboo bar strain curves of the typical specimens in group $\mathrm{ZB}, \mathrm{ZC}$, and ZD are shown in Figure 10.

The conclusions are as follows: (i) At the initial stage of loading, the strain of bamboo bars increases linearly.

(ii) The strain rate of the bamboo bars at the top of the column is the fastest, the strain growth rate in the 


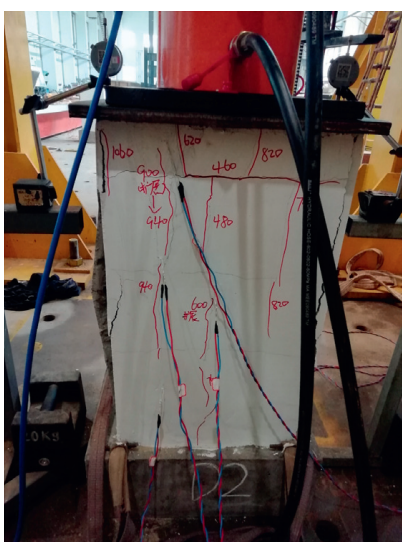

(a)

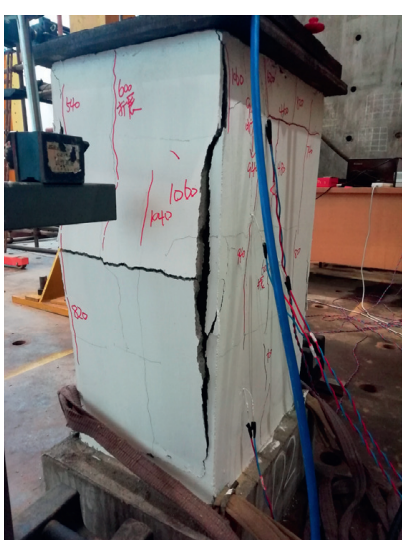

(b)

FIgURE 9: Typical failure of group ZD.

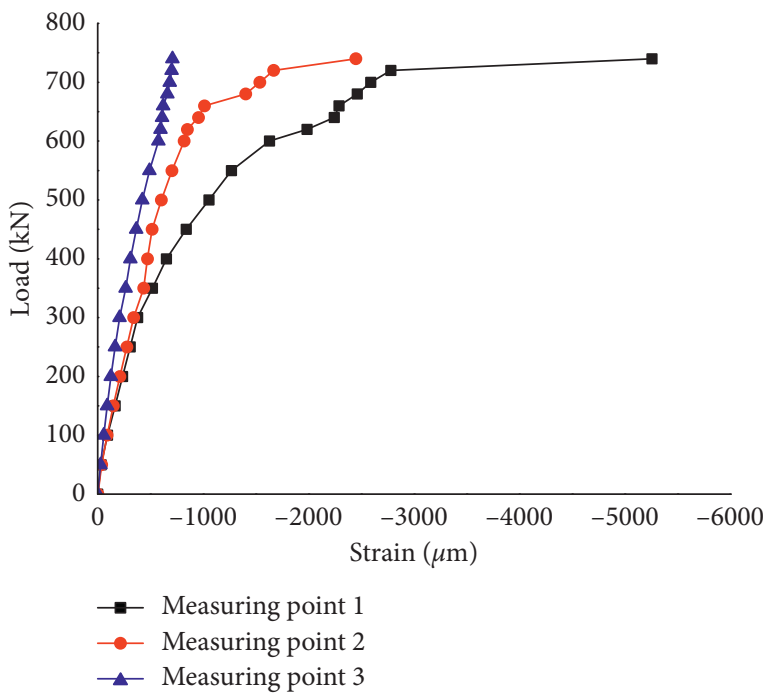

(a)

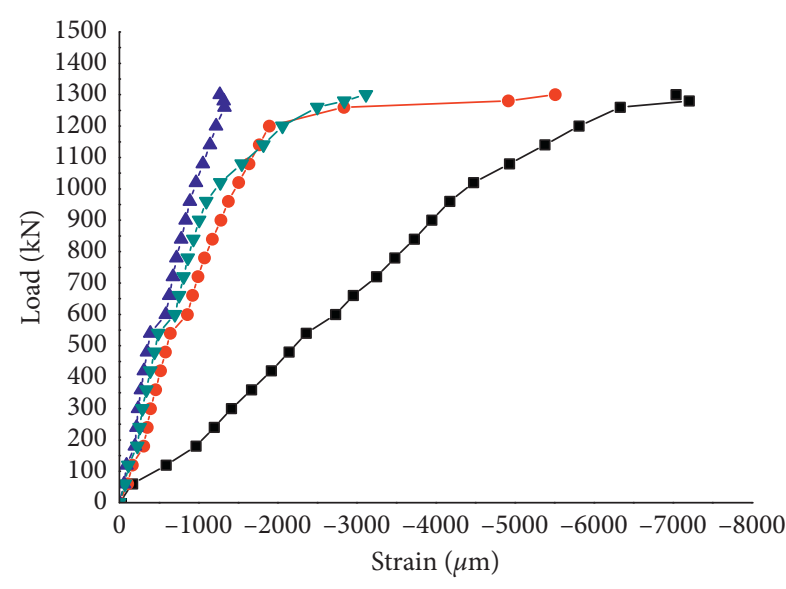

-- Measuring point $1 \quad-\boldsymbol{\Delta}-$ Measuring point 3

$-\bullet-$ Measuring point $2 \quad-\nabla-$ Measuring point 4

(c)

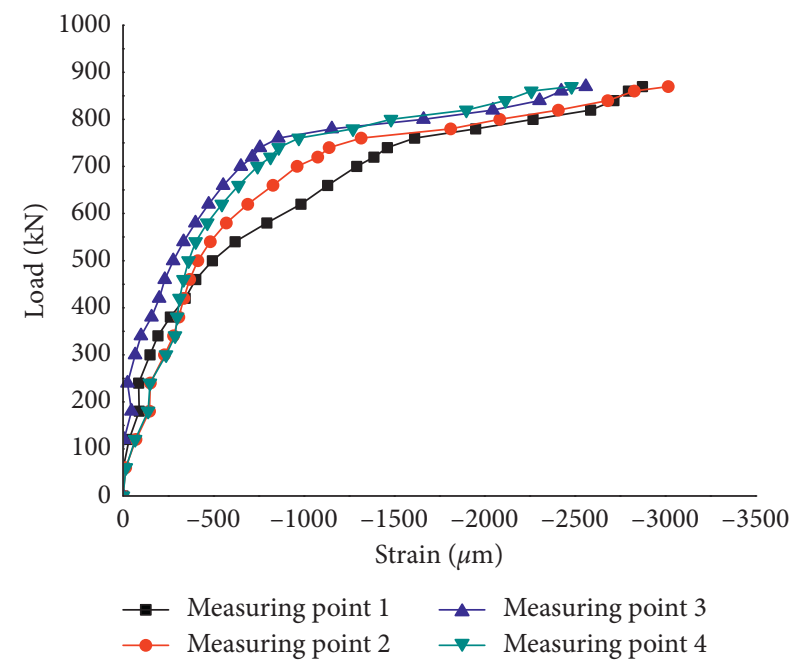

(b)

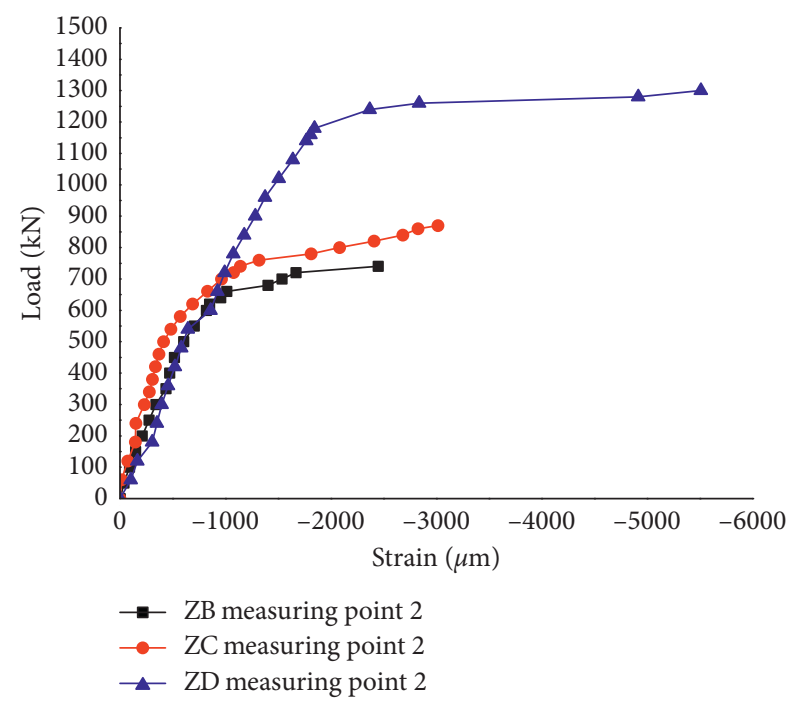

(d)

Figure 10: Load-bamboo bar strain curves: (a) ZB, (b) ZC, (c) ZD, and (d) comparison graph. 


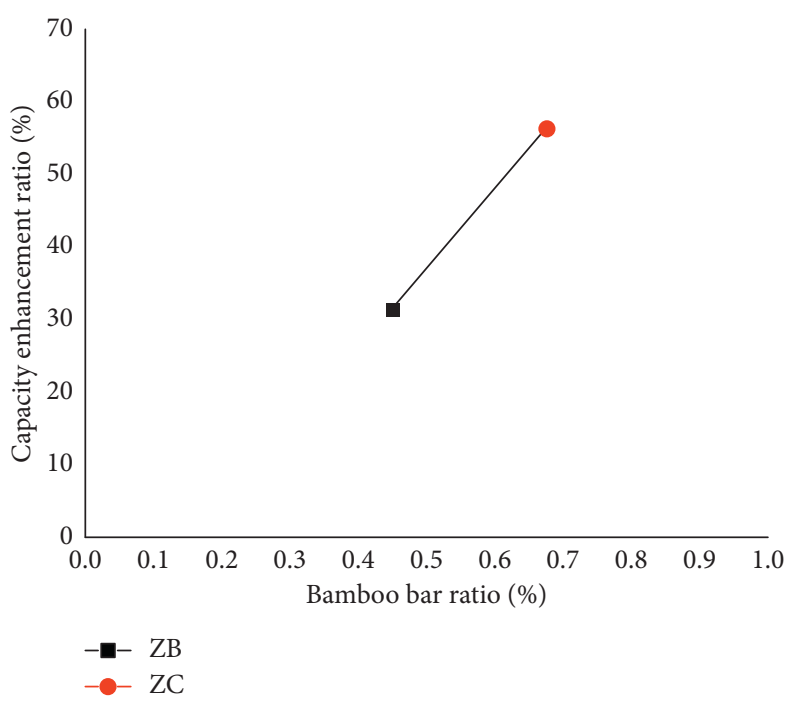

(a)

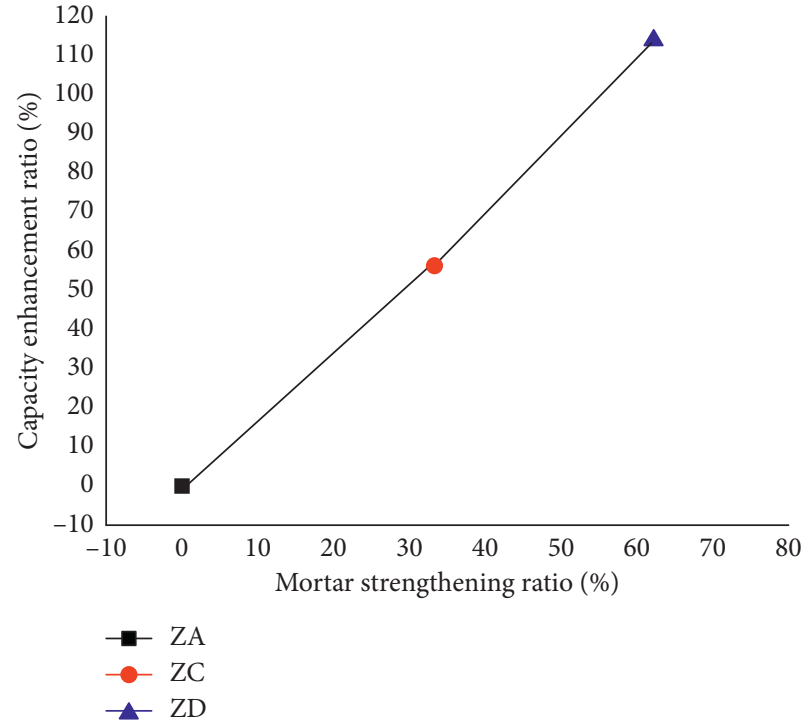

(b)

FIGURE 11: (a) Curve of bamboo bar ratio vs. capacity enhancement ratio. (b) Curve of mortar strengthening ratio vs. capacity enhancement ratio.

TABLE 6: Comparison between calculated and experimental values of the limit load of columns.

\begin{tabular}{|c|c|c|c|c|c|}
\hline Specimen & Experimental values $N^{\mathrm{t}}(\mathrm{kN})$ & Experimental values $\bar{N}_{0}(\mathrm{kN})$ & Calculated values $\Delta N(\mathrm{kN})$ & Calculated values $N^{\mathrm{c}}(\mathrm{kN})$ & $N^{\mathrm{c}} / N^{\mathrm{t}}$ \\
\hline ZB1 & 640.0 & 561.0 & 239.5 & 800.5 & 1.250 \\
\hline ZB2 & 740.0 & 561.0 & 239.5 & 800.5 & 1.082 \\
\hline ZB3 & 830.0 & 561.0 & 261.0 & 822.0 & 0.990 \\
\hline $\mathrm{ZC} 1$ & 890.0 & 561.0 & 341.9 & 902.9 & 1.014 \\
\hline $\mathrm{ZC} 2$ & 870.0 & 561.0 & 341.9 & 902.9 & 1.038 \\
\hline ZC3 & 870.0 & 561.0 & 232.3 & 793.3 & 0.912 \\
\hline ZD1 & 1300.0 & 561.0 & 657.3 & 1218.3 & 0.937 \\
\hline ZD2 & 1100.0 & 561.0 & 483.4 & 1044.4 & 0.949 \\
\hline \multirow[t]{3}{*}{ ZD3 } & 1200.0 & 561.0 & 459.0 & 1020.0 & 0.850 \\
\hline & & & & Average & 1.003 \\
\hline & & & & Variance & 0.013 \\
\hline
\end{tabular}

middle of the column is second, and the strain growth rate of the bottom of the column is the slowest. It shows that the deformation coordination ability of the bamboo bars and the brick column is good.

(iii) After the vertical load is increased to $650 \mathrm{kN}$, the strain of the bamboo bars increases rapidly in the group ZB. When the vertical load is added to $750 \mathrm{kN}$, the strain of the bamboo bars of group ZC developed rapidly. Compared with group $\mathrm{ZB}$, due to the increase of the number of bamboo bars, the axial bearing capacity and ductility of the brick columns of group ZC is improved. From these results, it appears that the compressive strength of the bamboo bars is more fully utilized, with the increasing ultimate strain of the bamboo bars of group ZC.

(iv) For the brick columns of group ZD, when the vertical load reaches $1170 \mathrm{KN}$, the strain of the bamboo bars increases rapidly. Due to the confinement effect formed by the four-side strengthening, the brick columns are in a triaxial compression state, and the compressive strength of the bamboo bars is efficiently used. When the specimens are destroyed, the strengthening mortar layers are arched, the middle brick columns are crushed, and the strain of the bamboo bars increases rapidly.

3.3. Strengthening Ratio. Figure 11 shows the effect of different mortar strengthening ratios and different longitudinal bamboo bar ratios on bearing capacity. The bamboo bar ratio is defined as the ratio of the total cross-sectional area of the longitudinal bamboo scrimber bars to the cross-sectional area of the unreinforced brick column. The mortar strengthening ratio is defined as the ratio of the total crosssectional area of the strengthening mortar layers to the cross-sectional area of the unreinforced brick column. We can observe in the figure that the bamboo bar ratio and the mortar strengthening ratio increase, and the axial bearing capacity of the brick columns is significantly improved. The 
increase rate of the axial bearing capacity of the specimens is approximately linear with the mortar strengthening ratio.

3.4. Design. According to the correlation analysis between the strengthening ratio and the capacity enhancement ratio of the brick column, the axial compression bearing capacity of the strengthened brick column can be simplified to the superposition of bearing capacity of the brick column and the strengthening layers. Refer to the calculation formula 6.2.1 of the external steel bar mesh mortar layer strengthening method in Code for design of strengthening masonry structures in [1] and propose the following calculation formula:

$$
\begin{aligned}
N & =N_{0}+\Delta N, \\
\Delta N & =\alpha_{\mathrm{c}} f_{\mathrm{c}} A_{\mathrm{c}}+\alpha_{\mathrm{b}} f_{\mathrm{cb}} A_{\mathrm{b}},
\end{aligned}
$$

where $N=$ axial bearing capacity of strengthened components, $\mathrm{kN} . N_{0}=$ axial bearing capacity of unstrengthened components, $\mathrm{kN} . \Delta N=$ compressive bearing capacity of the strengthening layer, $\mathrm{kN} . \alpha_{\mathrm{c}}=$ mortar strength productivity, take 0.75. $f_{\mathrm{c}}=$ strengthening mortar compressive strength, $\mathrm{MPa} . A_{\mathrm{c}}=$ section area of the strengthening mortar surface layer, $\mathrm{mm}^{2} . \alpha_{\mathrm{b}}=$ bamboo scrimber bar strength productivity, take 0.8. $f_{\mathrm{cb}}=$ compressive strength of longitudinal bamboo scrimber bar, $\mathrm{MPa} . A_{\mathrm{b}}=$ the sum of the section areas of the longitudinal bamboo scrimber bars, $\mathrm{mm}^{2}$

Using formula (1), the nine strengthened specimens of this experiment are calculated. Table 6 shows the calculation results.

\section{Conclusion}

The bamboo scrimber bars replace the steel bars and are used to strengthen low-cost masonry houses in rural areas, which is environmentally friendly. The bamboo scrimber bar mesh mortar layer can improve the cracking load, ultimate bearing capacity, and stiffness of the brick column under the axial pressure. With the increasing longitudinal bamboo bar ratio, the ductility of the brick column is improved. The strengthening layers improve the crack form and failure mode of the brick column. The four-side strengthening mode gives fullplay to the compressive strength of the bamboo bars compared with the two-side strengthening mode. According to the analysis of the test results, we propose the calculation formula of the axial bearing capacity of the brick column strengthened by bamboo scrimber bar mesh mortar layer. The calculation formula facilitates the application of the strengthening method in the strengthening and transformation of the masonry structures in rural areas.

\section{Data Availability}

Some data used to support the findings of this study are included within the article. All datasets generated during the current study are not publicly available because the data also form part of an ongoing study but are available from the corresponding author on reasonable request.

\section{Conflicts of Interest}

The authors declare that they have no conflicts of interest.

\section{Authors' Contributions}

Hongyao Liu and Min Lei contributed equally to this work.

\section{Acknowledgments}

This research was financially supported by the China Scholarship Council (Grant no. CSC201908430245). The opinions and findings in this paper are those of authors and do not represent those of sponsors.

\section{References}

[1] MOHURD, GB 50702-2011 Code for Design of Strengthening Masonry Structures, China Architecture \& Building Press, Beijing, China, 2011.

[2] G.T. Zhang, K.B. Shi, and Y.J. Li, "Experimental study on seismic behavior of brick walls strengthened with embedded bars," Journal of Building Structures, vol. 34, no. 5, pp. 145150, 2013.

[3] S. H. Farooq, M. Ilyas, and S. Amir, "Response of masonry walls strengthened with CFRP and steel strips," Arabian Journal for Science and Engineering, vol. 37, no. 3, pp. 545559, 2012.

[4] A. Darbhanzi, M. S. Marefat, and M. Khanmohammadi, "Investigation of in-plane seismic retrofit of unreinforced masonry walls by means of vertical steel ties," Construction and Building Materials, vol. 52, no. 2, pp. 122-129, 2014.

[5] S. Navaratnarajah and M. Kimiro, "Seismic behavior of low earthquake-resistant arch-shaped roof masonry houses retrofitted by PP-band meshes," Practice Periodical on Structural Design and Construction, vol. 17, no. 2, pp. 54-64, 2012.

[6] M.K. Deng, T. Li, and X.M. Fan, "Experimental investigation on axial compression of brick columns strengthened with HDC," Engineering Mechanics, vol. 36, no. 5, pp. 92-99, 2019.

[7] S.D. Salman, E.V. Carlos, and B. Nemkumar, "Seismic strengthening of unreinforced masonry walls using sprayable eco-friendly ductile cementitious composite (EDCC)," in Proceedings of the 6th International Workshop on Performance, Protection \& Strengthening of Structures under Extreme Loading (PROTECT2017), Guangzhou, China, December 2017.

[8] K. Yamamoto and K. Meguro, "The development of a new fiber reinforced for seismic retrofitting of masonry structures," in Proceedings of the 16th World Conference on Earthquake Engineering (WCEE2017), Santiago, Chile, January 2017.

[9] B. Sharma, A. Gatoo, M. Bock, H. Mulligan, and M. Ramage, "Engineered bamboo: state of the art," Proceedings of the Institution of Civil Engineers-Construction Materials, vol. 168, no. 2, pp. 57-67, 2014.

[10] N. Nurgroho and N. Ando, "Development of structural composite products made from bamboo II: fundamental properties of laminated bamboo lumber," Journal of Wood Science, vol. 47, no. 2, pp. 237-242, 2001.

[11] J.Z. Zhang, H.Q. Ren, Y. Zhong, and R.J. Zhao, "Analysis of compressive and tensile mechanical properties of recombinant bamboo," Journal of Nanjing Forestry University (Natural Science Edition), vol. 36, no. 4, pp. 111-115, 2012. 
[12] X.H. Zhang, E. Jing, Y.S. Li, and Y.T. Zhang, "Experimental research on compression and flexural mechanical performance of recombinant bamboo," Industrial Construction, vol. 46, no. 1, pp. 11-16, 2016.

[13] N. Nugroho and N. Ando, "Development of structural composite products made from bamboo I: fundamental properties of bamboo zephyr board," Journal of Wood Science, vol. 46, no. 1, pp. 68-74, 2000.

[14] D. Huang, Y. Bian, A. Zhou, and B. Sheng, "Experimental study on stress-strain relationships and failure mechanisms of parallel strand bamboo made from phyllostachys," Construction and Building Materials, vol. 77, pp. 130-138, 2015.

[15] B. Sharma, A. Gatóo, M. Bock, and M. Ramage, "Engineered bamboo for structural applications," Construction and Building Materials, vol. 81, pp. 66-73, 2015.

[16] M. Xu, Z. Cui, Z. Chen, and J. Xiang, "Experimental study on compressive and tensile properties of a bamboo scrimber at elevated temperatures," Construction and Building Materials, vol. 151, pp. 732-741, 2017.

[17] MOHURD, JG/T 199-2007 Testing Methods for Physical and Mechanical Properties of Bamboo Used in Building, China Architecture \& Building Press, Beijing, China, 2007.

[18] MOHURD, GB/T 50129-2011 Standard for Test Method of Basic Mechanics Properties of Masonry, China Architecture \& Building Press, Beijing, China, 2011. 